\title{
A Survey of Global Climate Justice: From Negotiation Stances to Moral Stakes and Back
}

Antonin Pottier ${ }^{1}$, Aurélie Méjean ${ }^{2}$, Olivier Godard ${ }^{3}$ and Jean-Charles Hourcade ${ }^{4 *}$

${ }^{1}$ Centre d'Économie de la Sorbonne, CNRS - Université Paris 1, France; antonin.pottier@univ-paris1.fr

${ }^{2}$ Centre international de recherche sur l'environnement et le développement (CIRED), CNRS, France

${ }^{3}$ Ecole Polytechnique, Department of Economics, France

${ }^{4}$ Centre international de recherche sur l'environnement et le développement (CIRED), CNRS, France

\begin{abstract}
Climate change poses immense problems of intergenerational, intragenerational and international justice. This critical survey describes the intellectual landscape of global climate justice, and clarifies the challenges, positions, arguments and theoretical background of this concept. To do so, we review how equity is mobilised in the climate change economics literature and confront arguments about justice used within or at the periphery of climate negotiations with those of moral and political philosophers. We present the stances of States, NGOs and experts. We discuss the principles of justice underpinning the fair sharing of a carbon budget and their moral justifications. We examine the concepts of climate damage and of responsibility and highlight the hurdles to make way for historical emissions in climate
\end{abstract}

${ }^{*}$ This survey owes a lot to the research of Olivier Godard on the topic of climate justice. See his latest book (Godard, 2017).

ISSN 1932-1465; DOI 10.1561/101.00000090

(C) 2017 A. Pottier, A. Méjean, O. Godard and J.-C. Hourcade 
justice. We conclude on some implications of the Paris Agreement for climate justice and the way forward.

Keywords: Climate change; climate justice; equity; emission budget; mitigation; historical responsibility; burden sharing; commons; ethics; climate negotiations

JEL Codes: A1, D6, F5, H4, Q54, Q56

\section{Introduction}

Climate change raises a number of justice issues.

Greenhouse gas emissions, the anthropogenic cause of climate change, impact natural environments and human societies with delays through their build-up into the atmosphere. Due to the inertia of the climate system, the impact of today's GHG emissions in terms of temperature increase will peak in 10-20 years, but will change the chemical composition of the atmosphere 'forever' (Archer and Brovkin, 2008). Some of the consequences will be felt within decades (temperature increase, ocean acidification), others will take centuries if not millennia to unfold (sea-level rise, ice cap melt). Is it fair to future generations to alter their environment this way? How can we reconcile the choices of past generations, the needs and wants of the present generation, and the interests of future ones?

Climate change impacts will affect different regions in very different ways. Some of the countries that will suffer the most are low GHG emitters (tropical African countries, small island states), whereas major emitters may benefit from climate change (Canada, Russia). Should the losses incurred by countries be compensated? If so, how? By whom?

Most GHGs contribute to climate change regardless of where they were emitted. There is a tension between the need to cooperate to reduce GHG emissions everywhere, the differentiated responsibilities of countries and individuals in producing the problem, and their respective capabilities to cope with stringent emissions reductions. What are then the principles guiding an equitable distribution of efforts? What procedures would ensure that these principles are chosen and implemented fairly? 
Climate justice is a growing field of ethical, economic and legal scholarship adressing these questions, as well as a rallying cry for those seeking a fair climate governance (Schlosberg and Collins, 2014). Debates, thoughts and proposals aimed at contributing to a definition of the content and limits of this concept are far more diverse than would appear after a rapid look at the most strongly voiced claims. The variety of positions is deeply embedded in fundamental debates on current moral and political philosophy.

The goal of this review is to propose a critical survey of the intellectual landscape of global climate justice, and to discuss some of the positions and arguments on the negotiation table and in the academic literature. For reviews with different scopes and details, see for instance, Okereke (2010) or Moellendorf (2012). Stern (2014a), a major voice in the field of climate change economics, has written his own personal review, while Gardiner et al. (2010) have provided a collection of landmark texts on climate justice.

Two strands run across our review. One is the extent to which moral prescriptions derived from a stylized ideal world are relevant in an economically and politically non-ideal world where various systems of beliefs and ethical traditions co-exist. Another touches on the possibility of defining standards of climate justice independently from the specifics of either economic mechanisms causing GHG emissions or natural processes of what we call 'a climate'.

To delineate the scope of our review, recall that justice has four main fields: procedural justice, based on the idea of fairness (fair access to expertise, public debate and decision-making; impartiality in considering the interests of all parties; free will for social transactions, etc.); restorative, corrective or compensatory justice for torts and damages unduly imposed upon victims whose rights are breached by certain members of society; distributive or social justice pertaining to the distribution of material and social resources (income, awards, property rights); retributive justice relating to the field of punishment. These fields are interwoven to some extent: for instance, procedural fairness is critical for the implementation of corrective justice. In this review, we mainly focus on distributive and corrective justice, giving only hints at procedural justice and leaving out retributive justice. 
We will use the distinction between global and local justice. Global ${ }^{1}$ justice concerns the design of just institutions within a polity. It considers general rules and principles valuable for society as a whole (Rawls, 1971). Local justice concerns the fair treatment of individuals in a specific situation of social interactions (buying goods at the supermarket, signing a contract for a job, etc.) within a given polity (Elster, 1992). When an issue is tackled as a local justice problem, it means that it should be solved under the constraints placed on the basic institutions and rules of society.

In an international context, as is the case here, a further relevant distinction opposes cosmopolitanism to internationalism. Cosmopolitanism considers individuals as the sole relevant, non-arbitrary subjects of moral consideration. Humankind, as a unique human community, should adopt just and fair rules: contingencies of birth (place, date) and nationality should not influence judgements. But humankind is not organised as a single society with seven billion members, it is composed of sovereign nations-states. Internationalism recognises that the existence of States does matter in moral and political terms, in the vein of Rawls (1993). It imposes specific constraints on international justice, such as the formal equality of states.

This review is organised as follows. We first examine how equity in the context of climate change is dealt with in the economics literature (Section 2). We then review the visions of justice underlying the building of the climate regime under the UNFCCC, and the various proposals made to shape the climate regime (Section 3). We discuss the principles on how a fair sharing of the access to the atmosphere should be organised, and their philosophical justifications (Section 4). We then examine the issues raised by historical emissions in the climate justice debate, discussing the concept of damages and the principles to identify dutybearers (Section 5). We conclude on some implications of the Paris Agreement for climate justice and the way forward.

\section{Equity and the Economics of Climate Change}

The economics literature on climate change has largely revolved around the question of the economic efficiency of emission reduction, using

\footnotetext{
${ }^{1}$ The term 'global' refers to a society, whatever the issue at stake, and not specifically to international or Earth system issues.
} 
well-established principles of public policy. The questions of whether we should act now or later and where should emission reductions take place have been addressed by the use of a discount rate and of the second theorem of welfare. According to this theorem, in first-best economies, a Pareto optimum can be reached in a decentralised way by a competitive market. This allows separating equity and efficiency: the allocation of emissions allowances over time does not influence the distribution of emission reductions, as a unique distribution of abatement efforts equalises marginal abatement costs across countries, irrespective of initial endowments (Arrow et al., 1995). This allows treating intra and intergenerational equity issues separately. In this section, we review the equity issues raised by this analytical framework in terms of intergenerational equity (Section 2.1), and we examine the question of intragenerational equity (Section 2.2).

\subsection{Setting the Target}

Following the seminal work of Cline (1992) and Nordhaus (1994), climate change has been approached in the economics literature as a problem of intertemporal consumption trade-off. Fighting climate change through costly mitigation measures lowers consumption today, but increases consumption in the future, because some expected losses from climate change are avoided. In this 'optimal climate change' framing, the final temperature increase, and the corresponding burden of mitigation efforts, is the result of a cost-benefit analysis (i.e. it is not set exogenously as a constraint). Most models assume a single agent per generation, and omit the question of the equity between individuals or regions at a given point in time. In this approach, economists have debated on the scale of mitigation efforts that are warranted, and, among other issues, on how it is influenced by intertemporal equity concerns. We review several points of contention.

First, the choice of the (consumption) discount rate is a highly debated topic, with numerous ramifications (Arrow et al., 1995; Stern, 2014b). Its decomposition through the Ramsey formula $r=\rho+\eta \cdot g$, where $g$ is the growth rate of the per capita consumption of goods and services, emphasises two parameters: $\rho$, the pure time preference rate (PTPR) or utility discount rate; and $\eta$, the elasticity of marginal utility of consumption. It has been argued that equity towards future generations commands a low (or even zero) PTPR, and thus high 
mitigation efforts (Stern, 2006). Fleurbaey and Zuber (2013) assume a zero PTPR and argue that a negative discount rate could be justified due to the uncertainty of future growth and the fact that climate policies have greater returns in bad climate scenarios. Low discount rates have been criticised for leading to sacrifice current generations in the name of future risks, since they lead to higher investments and lower consumption today. Nordhaus (2007) and Weitzman (2007) in particular questioned the use of a normative discount rate that would not reflect the real behaviour of agents. This issue is important, because a high pure time preference leads to crush the weight of climate damages in the discounted sum. Only a pure time preference rate close to zero, or the belief that climate damages could become catastrophic, can then justify climate action. How the elasticity of marginal utility of consumption, $\eta$, should be chosen based on an equity stance is a thorny matter because, in the standard utility model, this parameter conflates several dimensions of justice: intertemporal substitution of consumption along an individual's lifetime, the same across generations, intragenerational inequality aversion and risk aversion (Godard, 2009). Ha-Duong and Treich (2004) use an alternative utility model and disentangle risk and inequality aversion parameters. They show that higher risk aversion leads to higher abatement, while a higher inequality aversion leads to lower abatement. Berger and Emmerling (2017) propose a more general framework to disentangle the time, space and risk dimensions of inequity.

Second, the evaluation of climate damages is as crucial a step as the choice of a discount rate in any cost-benefit analysis. Aggregating damages is not simply a matter of summing monetary estimates in different regions. Regions have different levels of income, and individuals have different marginal utilities of income, so damages should be aggregated using 'welfare weights' (Azar, 1999; Fankhauser et al., 1997). The higher the inequality aversion, the larger the weight given to damages in poor countries, which increases the global damage estimate and warrants more ambitious mitigation efforts. Equity-weighted estimates of the marginal impact of emissions (or social cost of carbon) by region are used in models to reflect regional differences in terms of climate change impact and economic development, and their value may significantly impact the optimal level of abatement (Anthoff et al., 2009). Also, the degree of uncertainty on climate damages combined with the fact that 
they will be heterogeneously distributed among the world population may impact the optimal target (Schmidt et al., 2013).

In fact, the mathematical formula of the discount rate and the weights used to aggregate damages rest on the choice of the social welfare function. Discounted utilitarianism, that is standard in economic theory, has been criticized for not adequately representing the interest of future generations. Chosing alternative, more sustainable social welfare functions to discounted utilitarianism may result in more stringent optimal abatement policies (Botzen and van den Bergh, 2014). Chichilnisky (1996) suggests a class of welfare functions which account for the interests of both present and future generations, with the weighted sum of a discounted criterion and a criterion which accounts for the utility at infinite time. Roemer (2011) proposes to apply a sustainabilitarian (Rawlsian) social choice criterion to the issue of climate change, which gives priority to the worst-off. Dietz and Asheim (2012) introduce sustainable discounted utilitarianism, which prioritises the futures where consumption is lower than present consumption, and show that this favours stringent reductions of emissions. Fleurbaey and Zuber (2015) propose alternative criteria to discounted utilitarianism which incoporate a better prioritisation of the worst-off, and are more flexible in terms of population ethics and disentangle risk aversion and inequality aversion.

\subsection{Intragenerational Equity}

Global IAMs have been extended to include several regions (see for instance Nordhaus and Yang, 1996). Regional integrated assessment models calculate a global carbon price associated with transfers to satisfy the Bowen-Lindahl-Samuelson rule. Lindahl prices are differentiated by agent, so that each agent's marginal utility of the public good is equal to the opportunity cost of the resources each agent must forego.

These models assume that equity and efficiency can be separated, that is that the initial quota allocation does not impact the localisation of emission reductions, hence the overall efficiency of abatement. Equity is then usually considered as a matter of political choice. In a first best world, efficiency would be guaranteed by a unique carbon price, which could be implemented with any initial distribution of tradable emission quotas. Equity considerations would impact the initial distribution, 
but an equitable outcome could be reached independently from the economic outcome (here with a global carbon price). However, this conventional wisdom faces several difficulties.

First, Chichilnisky and Heal (1994) showed that, in the case of a public good produced in a decentralised way, equity and efficiency are no longer separable when no transfer is allowed between countries. Even when transfers are allowed, not all distributions of quotas are efficient, since redistributing wealth changes the optimum mitigation target (Chichilnisky and Heal, 2000; Shiell, 2003). Second, equity considerations also pervade the pure cost-efficiency analysis in a more technical way. Works on efficient carbon pricing in a multi-regional optimal setting use Negishi weights to separate the optimisation of the carbon price and the optimisation of the global income distribution (Nordhaus and Yang, 1996). For example, utilities that are logarithmic functions of national income are corrected with weights proportional to final income: this ensures a constant utility of a marginal dollar and guarantees that there is no redistribution of wealth among countries. The choice of these weights conceals equity issues (Stanton, 2011). In an intertemporal setting, Negishi weights actually carry an implicit view on how wealth will be distributed in the future, for instance as a function of the pace of economic catch-up of developing countries (Lecocq and Hourcade, 2012). But not all models use Negishi weights. Instead, Dennig et al. (2015) directly restrict the redistribution between regions by the social planner in a RICE-type model with income and climate damage distributions within regions.

Some studies have tried to bridge the gap between intertemporal and intratemporal equity concerns. Fo example, Tol (2001) studies three conceptions of equity (Kantian reciprocity, no envy from Varian (1974), inequality aversion), and shows how they impact both how efforts are shared and which atmospheric concentration level is finally reached in a regional IAM (FUND). Adler et al. (2017) also introduce an alternative to discounted utilitarianism in a regional model (RICE) and use a prioritarian social welfare function, giving priority to the worst-off.

Uncertainty on future climate impacts has featured prominently in the discussion of intergenerational justice, as it is, along with the irreversibility of committed warming, a key driver of ambitious climate policies. Uncertainty on mitigation costs has comparatively attracted 
less attention as an intragenerational issue, although defining a just burden-sharing in these risky situations is a thorny issue (see Fleurbaey (2010) for a general discussion). One reason for this lack of interest may be that mitigation targets agreed among countries are not set irreversibly, but can be adjusted over time as the uncertainty on mitigation costs in different countries is gradually resolved.

Another category of IAMs examines the cost-effectiveness of various transformation pathways to achieve a pre-defined climate target. These models account for the interactions between energy production and use, land-use change and economic and climate systems, and can be used to estimate the regional distribution of climate mitigation costs under various emission allowance schemes (Ghersi et al., 2003). These studies usually show that the regional costs of climate change mitigation may deviate substantially from the global mean, see for instance Luderer et al. (2012). In particular in a $2^{\circ} \mathrm{C}$ scenario, implementing a uniform carbon tax without compensatory transfers between regions would be achieved at very disparate economic costs across regions (Tavoni et al., 2013).

As a provisional conclusion, these works show not only how thinking on justice requires to consider economic processes dynamically sustaining the production of wealth, but also how implementing economic models and methods entails implicit or explicit normative choices on what is just.

\section{The Climate Regime and Equity Principles}

The global climate regime started to be established in the 1980s, with several international conferences on the greenhouse effect and the creation of the Intergovernmental Panel on Climate Change (IPCC) in 1988. It formally entered international law with the UN Framework Convention on Climate Change (UNFCCC), approved at the Rio summit in 1992. Since then, the climate regime has constantly been evolving and principles of justice have been invoked in this process (Okereke and Coventry, 2016). We review here the visions of justice underlying the negotiation process under the aegis of the UNFCCC (Section 3.1), as well as proposals made by governments or members of civil society to shape this regime (Section 3.2). 


\subsection{Visions of Justice Behind the UNFCCC Process}

The UNFCCC aims at stabilising 'greenhouse gas concentrations in the atmosphere at a level that would prevent dangerous anthropogenic interference with the climate system' (Article 2). Three principles of justice are used as guidelines for the actions to be taken to meet this objective: equity, responsibility and capability. Specifically, Article 3.1 states that: 'The Parties should protect the climate system for the benefit of present and future generations of humankind, on the basis of equity and in accordance with their common but differentiated responsibilities and respective capabilities. Accordingly, the developed country Parties should take the lead in combating climate change and the adverse effects thereof [emphasis added]'. In the name of these principles, the Western countries and the former Eastern block listed in Annex 1 of the Convention considered taking appropriate measures to bring their GHG emission level back to their 1990 value by year 2000. In addition, developed countries agreed to finance specific and commonly agreed action taken by non-Annex 1 developing countries for the sole purpose of mitigating climate change.

When the UNFCCC was adopted in Rio, climate policies were embedded within the promotion of 'sustainable development' (Article 3.4). A paradigm shift towards a more exclusively climate-centric approach occurred between the first Conference of the Parties (COP) in 1995 at Berlin and COP3 in 1997 at Kyoto. The Kyoto Protocol, adopted in 1997, assigned quantitative emissions targets for the 20082012 period to Annex I countries, with overall emissions of $5 \%$ below 1990 levels. These targets were accompanied by mechanisms of 'where' flexibility, including emission trading between states.

The all-pervading nature of energy use and the establishment of a global carbon market posed an unprecedented problem of fairness of the initial allocation of emissions allowances. This was the reason behind the Byrd-Hagel resolution of the US Senate stating in 1997 that it would not ratify a Protocol without a 'meaningful participation of developing countries'. It also motivated the Group of 77 and China at Kyoto to first veto the adoption of the Kyoto Protocol. This veto was only lifted thanks to the adoption of the Clean Development Mechanism which was supposed to enhance additional financial flows to support sustainable development in developing countries. Through this mechanism, Annex I countries could partially fulfil their mitigation 
commitments in non-Annex I countries (Lecocq and Ambrosi, 2007). As a result, mitigation by the North would help financing the (sustainable) development of the South. Despite this agreement and in the absence of any response to the 'entitlement' issue, the Group of 77 and China remained suspicious of international carbon trading, stating that 'until the question of emission rights and entitlements is addressed equitably, it would not be possible to have emission trading' (UNFCCC, 1998, p. 3).

The division between developed countries (with quantitative limits) and developing countries (with no such commitments) was considered as a stopgap, a first step towards a comprehensive agreement in the post2012 period. But in the span of 20 years, the world had considerably changed. This division became increasingly irrelevant for organising climate mitigation because the dominant share of industrialised countries in past emissions before 1990 faded away as emerging countries become major emitters (see Table 1). For example, China's emissions doubled between 1990 and 2005, making China the first global emitter since 2007, South Korean and Saudi Arabian emissions also nearly doubled in the same period. In per capita terms, this division was not meaningful either. The G77 encompasses the Gulf Arab states, which are the top emitters per capita, and whose per capita income is higher than that of many OECD countries. China's emissions per capita are comparable to the European average, but higher than the emissions per capita of some European states, like France.

A universal agreement was thus necessary and was expected to be reached at the COP15, convened in Copenhagen in 2009. Despite high expectations, world leaders failed to secure such an agreement. The top-down climate-centric approach focusing on sharing a carbon budget made it impossible to bridge the gap between Annex I and non-Annex I countries.

In 2010, the Cancun Agreements recognised the objective of limiting the mean temperature increase of the atmosphere below $2^{\circ} \mathrm{C}$ above pre-industrial levels. They introduced the concept of 'equitable access to development' (Winkler et al., 2011), and called for a 'paradigm shift' towards a development-centric approach aimed at re-directing development patterns towards a low carbon pathway (Hourcade and Shukla, 2013). The negotiation process aimed at delivering a legally binding instrument for the post-2020 period and at bringing all Parties under the same legal regime (Rajamani, 2012; Ranson and Stavins, 2012). These negotiations led to the Paris Agreement in 2015. 


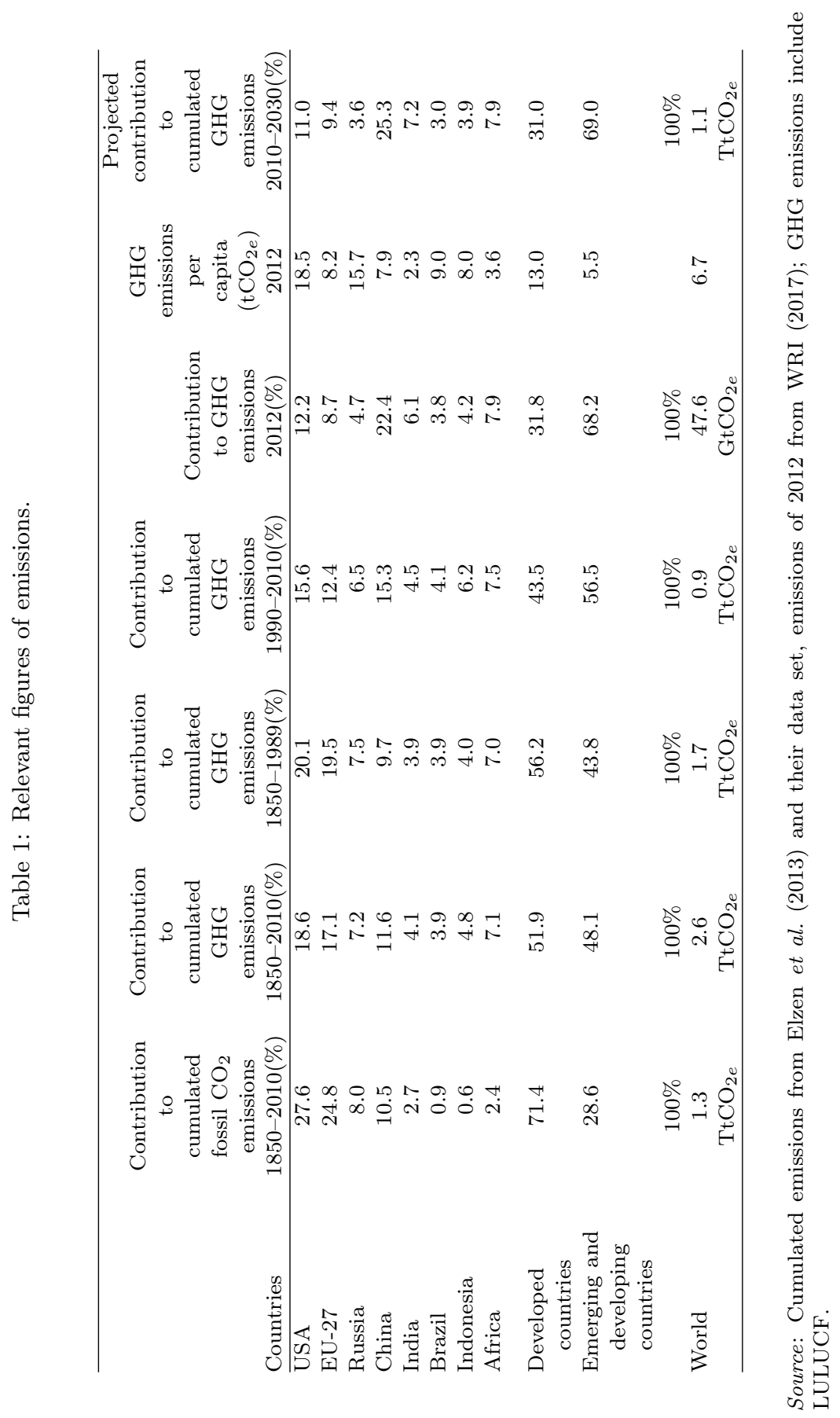


This legal regime, adopted by consensus by 195 countries, is legally binding under the internal laws and constitutions of the Parties. It is centered on the 'pledge-and-review' approach of the so-called Nationally Determined Contributions (NDCs), to be reviewed every 5 years. The question of how to finance the investments required in developing countries to mitigate and adapt to climate change has been central in climate negotiations, since developed countries committed to 100 billion dollars of transfers per year beyond 2020 at Copenhagen. Despite the demands of developing countries to benefit from financial transfers designed as just compensations for losses and obstacles to their development, financial mechanisms and flows from industrialised countries are still placed under the umbrella of aid and assistance.

\subsection{Review of the Main Proposals}

Many proposals were made to devise just and fair principles to allocate emissions rights or emission reduction burdens to countries. Below is a summary of the main ideas put forward by states, NGOs and experts.

\subsubsection{States}

- India: The distribution of emissions rights to countries should be based on their respective populations (Government of India, 2009). Justification: the atmosphere is a global public good; every citizen of the Earth has an equal right to use the atmosphere (Section 4.2).

- Brazil: The distribution of obligations to cut emissions should be based on the historical responsibility of countries in inducing global warming. This is the Brazilian proposal made on the eve of Kyoto negotiations. Justification: responsibility (Section 5.1).

- Bolivia: Developed countries should compensate the developing world for the damage already done and for obstacles to their future development imposed by constraints on the use of fossil sources of energy (State of Bolivia, 2009). Justification: victims should be compensated for any kind of damage done to them.

- France: The convergence of long-term emissions rights based on appropriate indicators (population, unit cost of $\mathrm{CO}_{2}$, GDP) 
and financial transfers to less-developed countries (AGBM, 1997; France, 2009). Justification: long-term equality of individuals in a world where development inequalities should progressively disappear (Section 4.2).

- United States: All countries should commit to controlling their emissions according to goals and targets they set themselves, while taking into account the commitments of other Parties. Justification: states are sovereign and no international institution can impose any rule. A climate change regime is about voluntary cooperation.

\subsubsection{NGOs}

Alongside government negotiators, numerous NGOs, groups and scientists have also elaborated discourses on climate justice, as their presence in COP side events gained momentum, especially after COP6 (2000). For example, a coalition of NGOs was established in 2002 as the International Climate Justice Network. They produced the Bali Principles of Climate Justice from which the following are extracted:

- Communities have the right to be free from climate change. This entails a general obligation for polluting countries to cut emissions with a view to eliminating them completely in the future. Concept involved: the 'right to a stable climate' (Section 5.2.2).

- Communities and indigenous peoples have the right to represent and speak for themselves, and to play a leading role in negotiations. Concept involved: 'procedural justice for communities at the bottom' (Section 4.5).

- Climate justice calls for the recognition of the ecological debt of industrialised countries; victims of climate change should receive full compensation, restoration and reparation for losses. Concept involved: 'full historical responsibility' (Section 5.3).

- Communities have the right to access renewable energy. Concept involved: 'technological justice': access of all communities to alternative, non-polluting technologies is a requirement of justice. 


\subsubsection{Experts}

The main discussions amongst experts about how GHG emission quotas should be allocated have focused on three variables: population, GDP and past emissions in a given reference year. Beyond the sharp differences in their distributive impacts, what stands out is the ambivalence attached to those variables. In fact, each of them can be used as a source of rights or alternatively as a source of obligations and duties:

- Population: allocate emissions quotas in proportion to the population of each country (theory of equal access rights for individuals to a common resource, Section 4.2) versus lower relative amounts for countries that have had a high level of population growth since 1990 (theory of state responsibility for their population dynamics; Grubb, 1995).

- Gross domestic product: according to a theory assuming that capacities are proportionate to GDP, more abatement should be asked of (and fewer quotas given to) countries with high GDP than of countries with low GDP (Section 4.4). Alternatively, GDP may be seen as a synthetic criterion of economic activity and then as an expression of physical requirements of GHG emission needs in order to sustain current economic activity, firstly of production and transportation of goods (Section 4.1).

- Emission levels at a given date (1990): this is the core of the opposition between those who call for quotas to be allocated in inverse proportion of their 'historical responsibility' or past 'excess use' (Section 5.1), and those who believe that, just like customary rights, levels of emissions at the moment when a new regime is put in place should be considered as the appropriate basis for organising initial steps in limiting GHG emissions in the future (Section 4.1).

Two additional criteria have been supported by some countries at certain times. Both target a situation of dependency that constrains the capacity to reduce GHG emissions:

- The area of the territory: the population/land density index and the area as such have significant impacts on land use and 
transportation needs, and therefore on GHG emissions: ceteris paribus, small and dense countries should emit less than large ones.

- The economic dependency on fossil energy sources: when countries generate considerable wealth through the exploitation of fossil energy sources or when consumer countries have no access to alternatives for meeting energy needs, this 'needs' constraint should be taken into account, claim representatives of Australia and OPEC (AGBM, 1997).

These proposals invoke various principles of justice, which we discuss in the following sections about the fair sharing of the access to the atmosphere and about the role of historical emissions in the climate justice debate.

\section{Fair Sharing of the Access to the Atmosphere}

Climate policies are often framed as a two-stage process: first, choose a target to avoid dangerous anthropogenic interference with the climate system, according to the UNFCCC objective (Section 3); second, share the burden of efforts (or allocate emissions rights ${ }^{2}$ ). This framing was prominent in the run-up to Copenhagen and has been reinforced by influential scientific articles (Allen et al., 2009; Matthews et al., 2012) that link long-term temperature increase to cumulative GHG emissions since the beginning of the industrial revolution. As a consequence, thinking about climate justice in terms of sharing a carbon budget has become commonplace and is still dominant today, although international negotiations have departed from this framing. In this section, we discuss the principles and philosophical justifications invoked to share a carbon budget between entities (mostly countries) in a given time frame. The shares of the carbon budget accruing to countries according to different rules can be found in Grasso (2012).

Discussions of climate justice principles give a prominent role to the contemporary interpretation of the propositions of Locke (1690) about the conditions of the legitimate appropriation of natural resources in

\footnotetext{
${ }^{2}$ Some authors distinguish burden-sharing and allocating emissions rights, see Müller (2001) for a discussion.
} 
their state of nature, that is even before the formation of political structures and the emergence of states. Like contemporary cosmopolitanists, Locke starts from the premise of a common property of terrestrial resources, which are spontaneously appropriated by some individuals. According to Locke, individuals in the state of nature are free and equal, as no social contract nor institution has yet transformed this state of nature into an organised society. Within this context, resources may be appropriated by individuals through their labour under two conditions: if there is 'still enough and as good left in common' for others to use (Proviso no 1), or if economic development enabled by the appropriation of resources allows those who do not have access to those common resources to be advantaged in terms of well-being (Proviso no 2).

We will encounter Locke's theory several times in our exposition of the justification of rules of emission allocations. We start with grandfathering (Section 4.1), as it has historically been the cornerstone of the climate regime, and we examine the following alternatives: equal emissions per capita (Section 4.2), the equity principle (Section 4.3), which can lead to more demanding conceptions of distributive justice, and the ability-to-pay principle (Section 4.4). Finally, we discuss implications on international justice of a Rawlsian premise according to which rules of justice (here for burden-sharing purposes) are aimed at organising social cooperation (Section 4.5). We defer the examination of the responsibility principle to Section 5, where historical responsibility in emission allocations is addressed together with the compensation of welfare losses due to climate change.

\subsection{Grandfathering and Customary Law}

Grandfathering symbolically refers to a specific moment of American history when, to establish their vote rights in elections, ex-slaves were asked to bring the proof these rights had been earned by their 'grandparents' and then passed on as a legacy. In economic contemporary debates, grandfathering means that a right has been obtained by past practices or that new rights should be distributed in proportion to the value reached by a relevant parameter that characterises the past (Robertson, 1995). This principle underpinned the Kyoto Protocol: emission caps were expressed as percentages of 1990 emission levels for developed countries, which comes to recognise that the situation of 1990 formed 
the appropriate basis to organise legal rights. The actual impact of grandfathering on the climate regime has thus been significant, although few have defended this criterion on moral grounds (Raymond, 2003, p. 166). For instance, Caney (2011, p. 88) sees no moral justification to this criterion, only pragmatic ones.

Bovens (2011) has attempted to defend grandfathering taking account of Locke's theory. He first argues that there is no fundamental difference between the atmosphere and public pastures, the access to which has often historically been organised according to grandfathering. Hence the suggestion that this method can also be considered to organise the rights of access to the atmosphere. However, he highlights two Lockean limits to this type of appropriation: (a) the conditions of appropriation must not threaten people's subsistence; (b) the appropriation becomes illegitimate if resources are wasted. For some authors, such as Singer (2002), Shue (1999) or Moellendorf (2011), these conditions are not met in the case of climate change: poor people will be affected in their basic needs and large amounts of GHG emissions are the outcome of luxury life-styles, that is a sort of waste. Whether the alleged violation of the first Lockean Proviso is sufficient to make the appropriation illegitimate can be questionned, as Godard (2017, Chapter 7) argues that this Proviso loses its validity in historical and transgenerational contexts.

Positive law can also shed light on a customary emergence of usage or property rights to the atmosphere. A customary right requires a repeated, sustained and generally admitted practice, in this case regarding the use of a natural resource (Byers, 1999). Before the discovery and public awareness of the impact of the use of the atmosphere on the climate, ${ }^{3}$ no one objected to the use of the atmosphere for discharging GHGs. Through the lens of customary law, the uses of the atmosphere prior to 1990 were legitimate (Godard, 1992; Young and Wolf, 1992).

However, strictly maintaining customary rights as of 1990 would mean setting in stone the unequal uses of the atmosphere, which would then become full ownership rights. Since the beginning of the interna-

\footnotetext{
${ }^{3}$ We will conventionally date this moment at 1990 , between the creation of the IPCC (1988) and the negotiation of the UNFCC (1992), see Friman and Strandberg (2014, p. 303). The first IPCC report (IPCC, 1990) was released that year. It is also the reference year for emissions in the Kyoto protocol.
} 
tional negotiations on climate change, the implicit agreement on the use of the atmosphere has disappeared: customary rights must give way to another regime formally negotiated among parties. Thus, two constraints must be satisfied: (a) the adoption of a new international legal regime cannot do away with past investments in infrastructure and production capacity that rely on techniques that emit GHGs; (b) relying on grandfathering should be limited to a starting point enabling a smooth transition from an unfettered use of the atmosphere to globally capped GHG emissions. This demand comes not only from Western developed countries, but from many states, including Gulf oil-producing countries, China and Brazil.

\subsection{Equal Individual Emission Rights}

Of all the propositions to organise the climate regime, the principle of equal emissions per capita has gained the widest support among moralists and NGOs. This proposition is appealing because it seems simple and resonates with the egalitarianism of modern societies (Dumont, 1986). For its proponents, the principle is self-evident, deriving simply from the common nature of the atmosphere and the principled equality of individuals (Baer, 2002).

The principle of equal emissions per capita can be applied on different time frames. It can provide a long-term target as in the 'contraction and convergence' proposals (AGBM, 1997; Meyer, 2000). This is the proposal put forward by France in climate negotiations (cf. Section 3.2). Many experts from the South apply this principle from the present day to compute carbon budgets by country: they simply allocate the intertemporal carbon budget of each country proportionally to cumulated population over the reference time period. Those who apply this method to include the past give way to account for historical emissions in fair sharing (Section 5). This is the principle put forward by India in climate negotiations (cf. Section 3.2).

This principle of equal per capita allocation was first articulated by Agarwal and Narain (1991) in their condemnation of the appropriation of international carbon sinks as a case of environmental colonialism. This principle has been defended by Singer (2002), who finds that 'this kind of equality seems self-evidently fair'. He argues that the use of the absorbing capacity of the atmosphere does not leave enough for 
developing countries, which violates the first Lockean Proviso; and that the least developed countries have not benefited from industrialisation, which violates the second. The atmosphere must then return to its status of an equally shared common resource. Singer only acknowledges one possible objection: the case where having the rich pay for mitigation eventually makes the poorest worse off through growth shocks and inefficient reallocation of economic resources.

Jamieson (2001) has highlighted the negotiation deadlock in the aftermath of Kyoto. To break it, he suggests combining a global emissions market (a demand from the United States), with a fair initial distribution of emissions rights (a demand from developing countries). He sets out several possible principles of distribution, but dismisses grandfathering as implausible. Allocation on the basis of productivity could be relevant, but only regarding the final distribution of emissions, not the initial allocation of emissions rights: emissions trading would ensure that GHGs are emitted by the most efficient producers. In the end, he finds equal emissions per capita to be the most plausible distributive principle because it is simple and 'morally unassailable'.

Starkey (2011) reviews the arguments to derive 'equal emissions per capita' from the commons nature of the atmosphere. He distinguishes between the atmosphere as commonly owned (res communis) and as unowned (res nullus). Some scholars, often among libertarians, do not support the assumption of initial common ownership: for them, the world was originally unowned but could be (and has been) appropriated. For egalitarian liberals who support the premise of common ownership, it is not straightforward for all of them to derive an equal right to emit from this common ownership, see for instance Risse (2012).

In addition to these objections, the principle is not as obvious as it may seem. Consider the proposition of Meyer (2013) that emissions should be equalised over the lifetime of an individual and not per annum. This argument weakens the self-evidence of equal annual emissions per capita. More generally, a limit of the intertemporal egalitarian approach comes from the uncertainty surrounding the size of future populations. Indeed, it would be impossible to share emission rights on a strict egalitarian basis among all individuals across all past and future generations, as one cannot legitimately predetermine the free choices of future generations in terms of procreation. A similar limitation arises when discussing the concept of historical responsibility (cf. Section 5). 


\subsection{Equity}

Equity is the first principle mentioned in the UNFCCC to allocate efforts aimed at protecting the climate system. This principle is certainly different from strict equality and may be more demanding. Unfortunately, the text is not specific on the way this principle should be interpreted. Vanderheiden (2008) suggests applying Rawls's difference principle: the principle allows diverging from strict equality if the alternative would make the least advantaged in society better-off, through time, than they would be under strict equality (Rawls, 1971).

Following this line of thought, emission rights should be allocated in an unequal way to the benefit of the poorest. Although Moellendorf (2011) first argues for the validity of equal individual shares on the grounds of Locke's theory, he eventually considers that this principle would exceedingly harm the most deprived parts of the population by further impeding their economic development: they should be allowed to emit more than the others. Shukla (1999) shares these reservations towards the idea of the long-term convergence of per capita emission rights, as it could impede the development of poor countries when they most need to emit GHGs. It would then be unjustly harmful if they had to purchase emission rights on the international market.

Some scholars disagree with the idea that the main concern when distributing emission rights should be the reduction of inequalities as such. They prefer giving the priority to improvements in meeting the basic needs of the poorest. Agarwal and Narain (1991) oppose subsistence emissions in the South to luxury emissions in the North. This idea has been supported by many since then. It points to the prerequisite that the allocation of emission rights should be sufficient to meet the basic needs of the population (Copp, 2005; Moellendorf, 2014). In the same vein, Shue (2009) suggests a principle of lexicographical priority for minimum survival emissions over the twenty-first century, assessed as the present level of per-capita emissions of India. According to Shue (2014), the share of emission rights that covers basic needs should be excluded from emissions trading.

However, emitting GHGs in the atmosphere is not a basic need per se. Satisfying basic needs is only loosely related to GHG emissions. The link is mediated by technologies, national infrastructure, social and political rights, geographical constraints, etc. The question then arises of the nature of what should be allocated to individuals. This refers to 
the famous "equality of what?" question asked by Sen. Caney (2009, 2011) and Posner and Sunstein (2009) argue that distributive justice should not consider a single good (here the absorptive capacity of the atmosphere regarding GHGs) independently of other goods which may also impact people's welfare. According to these authors, what matters to people is the whole set of rights on goods enabling the satisfaction of their basic needs. This argument echoes the debate on the ultimate goal to pursue: allocating equal rights to primary goods or to resources (Dworkin, 2000), or ensuring equal opportunities or equal capabilities?

Caney's solution to this problem is to find out which fundamental human interests are met by the rights to emit GHGs (Caney, 2011). It is at this level that equality should be searched for. Caney (2009) finds that if one considers the welfare of the whole population, the need to emit GHGs differs from one region to another, depending on geographical and climate constraints (for instance linked to heating), on economic conditions and on the availability of fossil fuels. Moreover, the equality of access to a particular resource is not sufficient to guarantee equity if people possess unequal capabilities to transform those resources into welfare. This directly relates to the debate between approaches based on resources, capabilities or welfare (Sen, 1979, 1992).

Another possibility would be to refuse to consider the distribution of GHG emission rights as a global justice problem addressing the full range of resources and goods. Helm and Simonis (2001) note that using wealth redistribution as the criterion for the rule of emission allocation changes the motive: the aim is then to transfer revenues rather than to distribute a common resource in an equitable way. Rather, they consider the issue in terms of local justice, and suggest to combine equal per capita emission rights and several criteria to ensure equity, notably Pareto-improvement and no envy. In the same vein, Gosseries (2005) also argues that the allocation of emission rights is an issue of local justice, and should be considered only in relation to the inequalities arising due to climate change, and separated from the more general issue of alleviating international distributive injustice for all the goods impacting welfare.

\subsection{Ability to Pay}

According to the ability to pay principle, parties with most economic resources should contribute most to reaching the common objec- 
tive (Jacoby et al., 1999; Shue, 1999). This principle relates to the UNFCCC's 'respective capabilities'. This kind of 'deep pocket' approach is purely instrumental and is not specific to climate change. Accordingly, individuals or states should reduce theirs emissions in proportion to their resources.

The question arises on how to measure the ability to pay, by income flows, a wealth index, or another yardstick. The Gross Domestic Product (GDP) is commonly used (Smith et al., 1993), for instance by experts (see Section 3.2). However, it does not account for the irreversibility of infrastructures and other rigidities affecting the geography and the economic development of each country. The pace of economic growth of a country may better reflect its ability to invest in infrastructures and alternative technologies, and re-organize housing and productive means in line with low-carbon requirements. In other words, a 'rich' country with zero or negative economic growth may not be able to adjust its infrastructures and productive capacities (which determine the level of its GHG emissions), while a 'poor' country with high economic growth may have some leeway to steer the development of appropriate physical capital.

Ability to pay can also be defined in the spirit of cosmopolitanism, based on the available income of individuals. For example, Baer et al. (2008) introduce a capacity index for each country. It is the sum of the part of individual incomes that are above a development threshold. If an individual is below the development threshold, he or she does not contribute to the capacity index of his or her country. Some proposals target the largest individual emitters, which are also the wealthiest. They build a global distribution of emissions from the national distribution of income, elasticity of GHG emissions to income, and emissions per country. Chakravarty et al. (2009) restrict emission reductions to the one billion high emitters whereas Piketty and Chancel (2015) explore various schemes for funding adaptation on this basis.

\subsection{Cooperation and International Justice}

Since the UNFCCC, the climate regime has been negotiated among states. In this context, the parties seek to find a system of rules and burden sharing that major states which are in a position to act (in other words the largest GHG emitters) may wish to join. Such a regime 
belongs to the realm of international relationships. The basic entities to consider are thus states, rather than individuals. We must then consider the same switch of central figures as operated by Rawls in his Law of Peoples (Rawls, 1993): international society is first and foremost a society of states, not a society of individuals.

In this perspective, the criterion of per capita allocation would generate a huge contradiction between the alleged foundation (equal citizens of Earth should have equal access to a common resource) and the universe and procedures involved (that of international relations): GHG emission quotas would be allocated to states and traded between states, not citizens (Godard, 1992; Posner and Sunstein, 2009). Wealth transfers would then accrue to governments, not low-emitting individuals. The same objections apply to equity proposals stemming from cosmopolitanist conceptions. How could justice be conceived in the universe of international relations between sovereign states? Referring to Rawls' views on the circumstances of justice can be useful at this point (Rawls, 1971, p. 126). The idea of justice is not a primitive, all founding concept, but is relevant only under circumstances in which civilised human cooperation may develop. Issues of justice arise because and to the extent that human beings need to cooperate. Invoking justice thus entails objective conditions, such as coexistence, comparable capacities and competence and mutual dependency to achieve one's own projects.

This can be applied mutatis mutandis to justice among states. To avoid dangerous climate change through mitigation policies, each state should be convinced that the proposed new regime will work for its own benefit, and not only the benefits of others or of humankind as such. To this regard, mitigation strategies that require international cooperation would be compared with alternative less-demanding strategies in terms of cooperation. Adaptation and unilateral geo-engineering may provide such 'alternatives' (Barrett, 2008), although not substitutes, to mitigation policies, in case cooperation cannot be achieved under acceptable conditions. States who are unsatisfied with the conditions of cooperation may pull out of any international convention, and cease to cooperate, as Canada did by formally withdrawing from the Kyoto Protocol in December 2012.

Since international cooperation is key to meet the central objective of the UNFCCC, the acceptability of solutions for cooperating parties is a basic requirement of any debate on justice and fairness. Approaches 
inspired by game theory (Barrett, 2003; Posner and Weisbach, 2010) underline the need to find a rule for burden sharing that ensures a net benefit for each party, that is it has to be a Pareto-improvement. Under international Paretianism (Posner and Weisbach, 2010, 2013), no country, and in particular no major emitter, should be a net loser in the new climate regime. This position has received some objections because it deems infeasible a redistribution of wealth that (minimally) already occurs today (Baer, 2013), or because no baseline reference scenario (compared to which one would be a net winner) can be agreed on (Jamieson, 2013).

Within international Paretianism, some principles and rules presented earlier could hardly be defended. For example, 'equal shares of carbon emissions per capita' would entail large transfers between countries. The net flow of income accruing to a country would be equal to the difference between the global average of emission per capita and the country average, times the population, times the price of allowances. For a modest carbon price of $30 \$ / \mathrm{tCO}_{2}$, with the data of year 2012 in Table 1, the net outflow would be 110 G\$ for the United States (around $0.7 \%$ of their GDP), and the net inflow would be $100 \mathrm{G} \$$ for African countries (5\% of their aggregate GDP). This would certainly not be acceptable for any US administration, and would undermine international cooperation.

The precedence of the principle of state sovereignty (Miller, 2007) means that any proposed international rule must pass the test of the free consent of each state under a fair international discussion and negotiation process. In this respect, a key component of international justice is the fair access of all states to international negotiations and to the governance of common institutions, such as green funds or different committees. This relates to one of the proposals put forward by the International Climate Justice Network (see Section 3.2). In the UNFCCC, the formal equality of states is the rule, as is the case in UN institutions. Each state has the same right of vote, and each can make propositions to the Secretariat of the Convention, or to the Subsidiary Body for Scientific and Technological Advice (SBSTA), a formal structure that explores the scientific and technical background of issues addressed by the Convention. The equality of voice has also infused into the policy-science interface. Improving developing countries participation was a major goal of incipient IPCC governance (Agrawala, 1998). 
Each working group has now two co-chairs, a scientist from a developing country and another from a developed country. There should also be at least one lead author from a developing country for each chapter. However, the representation of countries in IPCC reports is still imbalanced because most climate research is carried out in developed countries.

\section{Historical Emissions in the Climate Justice Debate}

The question of historical GHG emissions was put forward by the Brazilian proposal (Section 3.2). Several arguments can substantiate the need to account for historical emissions, although the initial proposition did not distinguish them. In a distributive justice framework, the problem of fair access to the atmosphere can be said to take its origin in the past. The overuse of the atmosphere by developed countries must then be balanced by a reduced allocation in the future to achieve a fair sharing of the atmosphere over centuries (Section 5.1). In a corrective justice framework, harm generated by excess emissions should be repaired. However, harm must first be identified: it can stem from a loss of welfare or a breach of rights. To this effect we discuss the concept of damage, highlighting the challenges of finding a definition from a moral perspective (Section 5.2). We then review two principles to identify duty-bearers: the responsibility principle (Section 5.3) and the beneficiary-pays principle (Section 5.4). We do not discuss the ability to pay principle (see Section 4.4) because there is not much more to be said from a moral point of view, as it does not link climate damages to the behaviour of those who are asked to pay for the debt.

In the climate case, the frontier between aspects pertaining to distributive justice and those pertaining to corrective justice is not easily drawn. The approaches are compatible, and are in practice often intertwined. Their consequences cannot always be distinguished. From a distributive justice point of view, past overuse must be balanced by future underuse, which grants more emission rights to presently low-emitting countries. However, if past overuse is seen as a tort, resulting damages should be repaired. This can be done by surrendering emission rights to victim countries, or by monetary payments. Harm unduly inflicted to victims can also be compensated in both ways. Thus corrective justice can also lead to a rule to allocate future emission rights. 


\subsection{Fair Sharing after Past Overuse}

The general principle of equal emissions per capita, discussed in Section 4.2 , can be given a retrospective strength. In that case, a carbon budget is defined as the maximum amount of emissions that could be emitted over a time period, say 1850-2100, to stay below a given target (usually taken as a $2^{\circ} \mathrm{C}$ increase compared to pre-industrial levels). This carbon budget is then allocated to states according to their cumulated population over the period. With such a retrospective process, the North will appear to have exceeded its fair share of GHG emissions. Its past overuse of the atmosphere is sometimes included in a broader category of the 'ecological debt' (Delord and Sébastien, 2010; Paredis et al., 2004) of old industrialised countries.

This line of argument has been formulated repeatedly by different countries and NGOs in combination with the idea of equal per capita distribution of emission rights. For instance, Teng (2009) develops a proposal based on a principle of equality of per capita cumulative emissions within an overall intertemporal budget of emissions calibrated to be compatible with the $2^{\circ} \mathrm{C}$ target. Khor (2009) suggests introducing the concept of 'negative emissions' to embrace all the obligations presently weighing upon industrialised countries; the latter are assumed to have exceeded their fair share of emissions to such an extent that their present rights should be nil and they should reimburse developing countries for the accumulated debt, either by creating sinks or by financing emission cuts in developing countries.

Regarding philosophical justifications, Neumayer (2000) advocates equal per capita emissions combined with historical accountability, stemming from the principle that all human beings are equal, independently from time and space. Moellendorf (2011) starts from the premise of a common property of the atmosphere and interprets it as giving equal rights to all individuals on its use. Historically, this appropriation has led to such consumption patterns in some states that there could not be enough carbon budget left to allow the same conditions to other countries, which literally contradicts the first Lockean Proviso. Moellendorf (2011) doubts that the second Lockean Proviso has been observed in reality: it has not been established that the global economic growth stemming from excessive GHG emissions since 1850 generated benefits large enough to compensate the victims of climate change for the caused 
damage. Meanwhile, it has not been established either that the likely victim countries would have been better off if common property and equal access for all had been maintained historically at the price of lower economic growth. Finally, Moellendorf considers that Locke's theory supports the idea that the countries which emitted more GHGs than their equal share should compensate those which did not.

In the name of a cosmopolitan priority view, Meyer (2004, 2013) offers a different way of giving a room for historical emissions in allocating fair access to the carbon space. Meyer places his proposal in the framework of a general distributive requirement, indifferent to issues of wrongness or injustice of past emissions. Hence historical emissions count in only two ways. First, he assumes that a principle of equal per capita benefits from emission rights should be understood not for each point of time, but in a cumulative way for the whole lifespan of individuals. Presently living agents should thus receive emission rights for their future activities by a share taking into account the amount of emissions of which they have already benefited since their birth. Because living inhabitants of developed countries have personally, on average, already emitted much more than those of developing countries, they should receive less than an equal share for their remaining time to live. Second, currently living inhabitants of developed countries are still enjoying some lasting benefits of past activities allowed by GHG emissions as by-products. So the past GHG emissions of ancestors are still procuring benefits to currently living individuals. Then, according to a norm of universal equal per capita benefits gained from emission rights, those who presently enjoy benefits from past emissions should get, in proportion, fewer new emission rights in the future than the strict equal share.

\subsection{Defining and Assessing Climate Change Damage}

Traditionally, damage has been defined as the economic consequences of climate change, as opposed to impact, which is the effect on biophysical systems. This 'damage' is a welfare loss, but not damage in the legal or moral sense, which refers to the harm generated by a wrongful behaviour to a protected interest. As this distinction is central in the following discussion, we will use the term 'damage' only when a moral-legal connotation is implied, otherwise we will use the more neutral term 'loss'. 
Welfare analysis, which is common in climate change economics (Section 2), blurs this distinction because its relies implicitly on utilitarian philosophy. It raises a difficult issue of utility comparisons. The most common approach assumes the permanence of individual and collective identities (the United States, China, France, etc.) and compares welfare positions of these entities in different scenarios. This could result in statements such as: 'people living in 2100 will suffer welfare losses due to climate change'. Being acceptable at first sight, such statements are nevertheless logically unacceptable since the people in the different scenarios under comparison are not the same. What can be said is only: 'people living in 2100 in region $\mathrm{X}$ under climate change will have a lower welfare than the people that would be living in the same region if there was no climate change'. Here we uncover the famous non-identity problem.

\subsubsection{The Non-identity Problem}

The people living in the first scenario would be different from the people who would be living in the counter-factual scenario without climate change, in both number and quality. This is the non-identity problem (Parfit, 1984). According to ethical individualism (which recognizes the unique identity of each individual), future individuals will never be in a position to blame past generations for the state of the world they inherit because, if those past generations had behaved differently on a large scale, those particular individuals may never have been born. In the case of climate change, people who suffer from losses generated by climate events cannot claim that they suffer from unjust harm caused by past generations because they would not have been born, had past generations behaved differently.

This non-identity argument dismisses any concept of intergenerational justice based on the potential blame of previous generations by future ones. To avoid this objection, Meyer (2004) proposes to define harm in an objective way by setting a decent well-being threshold that should be secured for all living and future individuals. This shifts the problem from the framework of corrective justice to that of distributive justice. It is the fact that some individuals may fall under the wellbeing threshold that would violate Meyer's sense of justice. Still, in order to determine whether or not this fall can be imputed to climate 
change, it would be necessary to compare the state of well-being of future individuals under climate change with a counterfactual without climate change. Here the non-identity problem returns (Godard, 2017).

\subsubsection{The Scope of Acknowledged or Implicit Rights}

A second difficulty is that damages in the moral or legal sense depend on the scope of acknowledged or implicit rights of individuals. The famous argument of Coase (1960) underlines the reciprocal nature of positions of agents affected by environmental issues: if the respective rights have not been defined by an institution, it is impossible to describe a situation in terms of damage caused by one person and suffered by another; there are just conflicting usages of the same assets. If we assign roles of polluters and victims of pollution, it means that we have implicitly granted the latter with a 'natural right' to given environmental conditions. Without any generally acknowledged definition of protected rights of individuals regarding climate conditions, it is inappropriate to speak of damages caused by GHG emitters.

Several tentative definitions of protected rights have been proposed. If adopted, then breached, they would open the way to compensatory measures. We have already introduced the 'fair access to atmosphere' that would be breached by the overuse by major emitters. Caney (2005) invokes the right of people not to suffer from losses stemming from global climate change, although this right has no equivalent in positive law. Vanderheiden (2008) claims that individuals have a right to climate stability. The right to a stable climate has been put forward by NGOs in the context of climate negotiations (cf. Section 3.2). However, the existence of a natural right to an unchanged climate and an unchanged local environment could be questioned. Climate exhibits multi-decadal natural fluctuations at the regional level. Moreover the claim to a right on an object requires that this object is within the control of human action. However, local environmental conditions are unstable and intangible objects, and therefore cannot be easily subjected to such rights. Wind, rain and temperature escape human control at the local level. The reduction of GHG emissions does not allow controlling specific climate events, but only influences the general statistical trend of climate events as a whole at the regional or global scale. 
Many analysts and activists such as Mary Robinson Foundation Climate Justice (2011), Shue (2011) and Koivurova et al. (2013) link human rights and environmental protection. Consider, for example, the arguments of Caney (2010b): climate change violates the right not to be arbitrarily deprived of life, because of extreme weather events such as storms or floods causing deaths. The link between climate change and the ultimate deaths is more tenuous than argued. First, the relation between climate change and a particular extreme event is only probabilistic. Although attribution studies of extreme events have made some progress (Coumou and Rahmstorf, 2012; Otto, 2016), they generally cannot prove that an extreme event would not have occurred in the absence of climate change, but they can (and sometimes do) prove that climate change increases the probability of such an event occurring. Second, the impacts of extreme events on local population highly depend on socio-economic conditions and their evolution. Climate change is only a factor among others, and other dimensions of risk, such as vulnerability or exposure, are also important (Huggel et al., 2013). This certainly puts serious obstacles to attributing specific, or even probabilistic, deaths to climate change.

The evolution of the environment in general, and the climate in particular, impacts the way basic rights can be enforced in a local society. However, it is not an infringement of rights per se. Life, subsistence and health do not directly and solely depend on the climate, but depend first and foremost on the level of development of a country, on social and economic rules, public health policies, social security institutions and mechanisms to assist the victims of natural disasters. The association of climate and basic rights falls too often in the trap of climate determinism.

The difficulty to define climate damages is reflected in the climate regime, which has only recently addressed them. The Warsaw International Mechanism for Loss and Damage was established in 2013, at the pressing demand of the Alliance of Small and Island States. It did not mention compensation and mainly focused on knowledge sharing and cooperation. Damage, however, raises justice issues beyond compensation. Huggel et al. (2016) argue that climate change impacts are not well documented in developing countries because fewer observations are available, and over a shorter time span. As a consequence, developing countries suffer from a procedural injustice in the detection and attribution of impacts. 


\subsection{The Responsibility Principle}

\subsubsection{Searching for a Consistent Concept of Responsibility}

According to the responsibility principle, emission reduction efforts should be shared in proportion of the responsibility of states in creating the problem in the first place. The responsibility principle is also invoked when it comes to correct climate losses. In the original Brazilian proposal, developed countries would share the emissions rights in inverse proportion to their historical responsibilities since 1850 (cf. Section 3.2). Following this proposal, the SBSTA was asked to document the idea and elaborate methodologies aimed at practical use, and fostered research on national historical emissions, methods of attributing responsibility, etc., see Friman and Strandberg (2014) for an extensive review.

There remains considerable uncertainty on historical responsibilities of climate change, but political choices (when to start? which emissions count?) have still more impact than scientific choices (which data set? how to distribute causes?) on the implied distribution of responsibility (Elzen et al., 2005, 2013; Müller et al., 2009). In practice, cumulative emissions are often taken as a proxy for historical responsibility, although this implicitly endorses a particular stance on what responsibility is. And it is solely when one considers emissions from fossil fuels only that the contributions of developed countries appear overwhelming, whereas counting all GHGs and LULUCF emissions gives a more balanced picture (compare the first two columns of Table 1).

Responsibility is not equivalent to causality and is laden with moral connotations. Miller (2007) has offered a thorough discussion of the concept of responsibility. He distinguishes three different meanings. The less demanding one, 'causal responsibility', focuses on the causal chains involved, without accounting for morally relevant subjective aspects such as intent, diligence, negligence and predictability. It responds to a scientific viewpoint. With 'outcome responsibility', the causal component remains, but it is supplemented by genuine agency conditions: a foreseeable connection between acts and consequences, avoidable consequences by cautious action, absence of coercion and manipulation. Actual intent and forecast are not necessary conditions but circumstances have to be such that reasonable persons who know 
about the risks involved for others would have taken action to avoid the bad consequences imposed to them. This second meaning may still be too broad to be applied to climate change. For instance, according to outcome responsibility, any efficient firm putting some other less efficient firms out of business would be asked to refund losses of the latter. Miller then comes to the moral concept of responsibility that may be more relevant for climate change: assuming previous conditions (causality, predictability) are met, 'moral responsibility' may be involved when causal agents have acted in a faulty way by not respecting pre-existing moral obligations, for instance by breaching the rights of others. In order to give substance to the concept of historical responsibility, faults have to be proven.

In the literature, responsibility is nearly always attributed to collective entities such as nation-states, although targeted entities could also be corporations (Caney, 2005), or trans-generational groups (families, dynasties). Heede (2014) and Frumhoff et al. (2015) have attempted to trace the responsibility of fossil energy companies in climate change. In the case of trans-generational groups however, this would require the whole history of each family to be traced back to year 1850, which is obviously impossible.

The idea of making historical responsibility the basis of rules of allocation of efforts and rights between countries has been strongly contested at the table of international negotiations as well as in the academic debate (Miller, 2009; Moellendorf, 2014; Risse, 2012). Placing the whole burden of tackling climate change on GHG emitting states would be the same as considering that the rights of the victims of climate change are superior to the rights of emitters, although, to different degrees, emitters and victims are the same people. Instead, Chauvier (2013) suggests using a balanced polluted-pays principle in cases of conflicts between equally legitimate rights: the victims of pollution should be granted a right to ban the pollution, provided that they compensate the polluters for the cost of abstaining from the pollution. Alternatively, the mutual compensation principle explored by economists states that the victims should cover the costs incurred by emitters for reducing their emissions, while emitters compensate victims for their losses, provided that the losses are in violation of established rights (OECD, 1976). We review the main objections to the responsibility principle in the following section. 


\subsubsection{Responsibility, Knowledge and Control on Past Emissions}

According to Aristotle's theory of virtue, a human person cannot be held morally responsible for damage suffered by others if he or she is ignorant of this damage or has no control over the events involved. Regarding historical emissions, the condition of knowledge was not met before a point we date conventionally at 1990. In fact, generations who died before then may have ignored that their use of fossil fuel would have impacts across the planet. Therefore, people before 1990 could not reasonably be held responsible for not changing their activities and living conditions (Bell, 2011). Even the conditions of 'outcome responsibility', in Miller's terms, are not met since it refers to what normal people would do, and normal people all over the world demonstrated no climate concern before 1990. A counter-argument is that although ignorance dismisses moral guilt, it may not dismiss liability, as shown by rules of strict liability admitted by some legal systems (Shue, 1999, 2009), a position shared by Neumayer (2000), Vanderheiden (2008) and Gardiner (2011), but deserving critical examination. It is critical to the justification of strict liability that all agents have full conscience ex ante that this rule will be applied in case of violation of safety rights, a condition that is not met in the context of 'historical responsibility' for climate change before 1990 (Moellendorf, 2014; Schüssler, 2011).

After 1990, the issue of responsibility has a different nature. Indeed, as of 1990, countries could have been expected to know about the danger of climate change (Parikh and Parikh, 2009). Then, the question becomes whether states or individuals are responsible for not having sufficiently changed their economic activities and lifestyles, considering the risk of climate change. If, following Gardiner (2011), one sees the precautionary principle as the source of a moral obligation to act and understands it as an obligation to absolutely avoid a suspected hazard, it would follow that all means should have been used to avoid the possible catastrophic consequences of climate change as soon as the possible severity of the threat was known. But this is a very particular understanding of the requirements of the precautionary principle, for instance not shared by other scholars (Sunstein, 2005) or by the EU doctrine (European Council, 2000). Historically, the UNFCCC and the Kyoto Protocol have been the real-life political and institutional translation of the precautionary principle with regard to climate change: they aimed precisely at avoiding dangerous anthropogenic interference 
with the climate system. One could therefore argue that citizens of the states that achieved their objectives under the Kyoto Protocol lived up to their obligations. However, Gardiner (2011) and Shue (2014) find the Protocol inadequate, as it would not prevent significant losses for the most vulnerable. Following Pogge (1994), they consider that the citizens of developed countries are responsible for the inadequacy of their governments' response to the threat of climate change. ${ }^{4}$

A more serious objection than lack of knowledge is supplied by the argument of the absence of control of present generations on the past behaviour of their ancestors. It would be unfair, so goes the argument, to proceed as if generations living since 1990 were responsible in place of past generations over behaviours of whom they evidently had no control. If any, the specific liability of developed countries should be limited to the emissions of those living people at the time of negotiating a new climate protection regime.

In any case, the losses caused by the emissions of any generation cannot be identified without ambiguity. As emissions are persistent in the atmosphere and the climate system reacts with delays, observed losses at a given time can only be causally attributed to the level of global GHG atmospheric concentrations reached at that time, hence to the outcome of the emissions path as a whole. The attribution of losses to emissions at a particular date is an intellectual construct that requires the definition of models fed by a number of assumptions. The future losses attributed to present emissions depend on the future path of GHG emissions, hence on the choices that will be made by future generations. The control over these choices is not absolute (Tol, 1998). All this means that the amount of presumed losses attributable to our emissions is not fixed at the moment these emissions occur, and depends on the future behaviour of our grandchildren, as the losses attributable to our grandparents' emissions depend on our own behavior.

\subsubsection{From a Cosmopolitan Perspective}

Historical responsibility causes further difficulties within a cosmopolitanist view. Being grounded in moral individualism and the rejection

\footnotetext{
${ }^{4}$ Also, the question remains of the obligations of the citizens of states that did not sign up to the Protocol or withdrew from it, and to the citizens of states that were assigned no objective of emissions reduction under the Protocol.
} 
of borders and states as arbitrary and insignificant features, cosmopolitanism cannot thereafter focus its arguments on those collective entities such as 'nation states' to define obligations and fair burden sharing through GHG quota allocation. A cosmopolitanist cannot for instance support Miller's theory of collective national responsibility and the inheritance of remedial duties (Miller, 2007) to save the construct of the historical responsibility of industrialised countries. Indeed, collective responsibility breaches the premise of moral individualism according to which only individuals are moral agents to whom obligations and duties can be assigned.

Since GHG emissions are intertwined with nearly every human activity, and past human history is also made up of intertwined events and relations, past GHG emissions are arguably either those of humankind, globally, or those of individuals taken with their family links and heritage. The same argument could be made regarding present inequalities of wealth, which are as large within emerging and developing countries as they are between developed and developing nations. To be coherent, cosmopolitanism should deliver solutions that are not restricted to the level of States and account for individuals. But, by making prescriptions interfering with the domestic organisation of states and their social order, cosmopolitanism would frontally violate the principle of sovereignty and the type of relationships states may have in an international negotiation.

\subsubsection{A Case of Retrospective Illusion}

Godard $(2012,2017)$ argues that the historical responsibility scheme is prisoner of a 'retrospective illusion'. This illusion arises when one interprets past history as a one-way deterministic sequence on the basis of the knowledge of end results. It then attributes to human agency, at different moments of the past, various wrongful factors that directly proceed from the knowledge of actual end-results.

Not only did past generations not know about the threat of climate change as a possibility before the 1970 s or as a serious while still uncertain threat since 1990, but historical emissions were the source of no significant damage until 1990. If we accept $350 \mathrm{ppm}$ as a safe concentration level (the most stringent target proposed by NGOs (e.g. 350.org) or scientists (Hansen et al., 2008)), it is important to note that this level was only reached around 1990. Moreover, the recent course of GHGs 
emissions since 1990 was not a predictable fate. Other counterfactuals could have led to a future without any climate change. At these past moments, climate change had no present and future reality, being just a conditional possibility among many other possible historic evolutions that would give rise to no man-induced climate change. Climate change was not a determined, predictable fate.

Retrospective illusion is commonly used to blame developed countries for their past behaviour. It can also be used by some countries to appear in a better light, when past actions are retrospectively seen as mitigation. For example, in its first national climate change strategy, China considered that its 'one-child' population policy in place since 1979 contributed to mitigating GHG emissions (China, 2007, p. 11), with estimated avoided emissions of $1.3 \mathrm{GtCO} 2$ in 2005 . Thanks to this redefinition of the reference case, China could thus claim that it already had significantly contributed to mitigate global climate change.

\subsection{The Beneficiary Pays Principle}

The beneficiary pays principle has been proposed as another principle to identify duty-bearers to overcome the critiques raised against the responsibility principle (Baatz, 2013; Gosseries, 2004; Page, 2012). The argument is the following: even if present people are not causally responsible of damage suffered by victims, they still enjoy benefits and wealth from the activities of their ancestors that causally generated the damage. They would have a moral obligation to disgorge the benefits gained from injustice and refund the victims. This position was previously endorsed by Shue (1999) and Beckerman and Pasek (2001).

\subsubsection{Wrongful or Unjust Enrichment From Past Emissions}

Page (2012) introduces a distinction between two sub-cases to justify the beneficiary pays principle: (a) wrongful enrichment and (b) unjust enrichment. According to (a), states should pay compensation to victims in proportion to the present benefits those states enjoy as a result of wrongful past activities. The extent of net benefits gained by beneficiary states would set the upper limit to the compensation to disgorge. Implementing this principle is conditional on the establishment of a clear violation of victims' rights by past generations. Due to 
difficulties of proof of the latter, Page prefers version (b) of the principle, which assumes no fault from causally responsible agents. Applied to climate change, the claim is therefore that industrialised countries have been enriched by activities incorporating an 'unjust factor' - GHG emissions. Page puts several arguments forward to this effect. First, the distribution of benefits and adverse effects is unequal, even in full respect of legal rights of all parties: for decades, adverse effects were imposed on developing countries, whereas benefits were mainly directed to developed countries. Second, Page argues that developed countries have deprived developing ones of the opportunity to push their own present and future development without having to care about GHG emissions. Indeed, developing countries face a trade-off between economic development and avoidance of a dangerous threat on the global climate, a trade-off that developed countries did not have to worry about several decades ago, and this is unjust. Third, the atmospheric capacity to absorb GHGs, as well as a majority of ocean sinks, is said to be a global common property by nature, a property of which developed countries have made an excessive and unjust usage. Several of these arguments have already been mentioned and discussed.

In fact, the beneficiary pays principle cannot apply to any unequal enrichment. It is not sufficient to observe differences in the distribution of benefits of industrialisation across regions of the world: there has to be something wrong or unjust in the behaviour of past generations. Let us examine these points.

\subsubsection{Limitations}

Miller (2009), Caney (2006, 2010a,b), Kingston (2014) and Huseby (2015) all argue against the beneficiary pays principle. Caney (2006) invokes the non-identity problem. The parables picked by Kingston (2014), and inspired by Miller (2001), point out to the idea that the beneficiary pays principle can only reasonably be invoked if the harm caused is the result of a faulty conduct from the causally responsible agents, which refutes Page's second justification of the principle. Also, Goldemberg and Guardabassi $(2012,2015)$ refute Page's argument, stating that developing and emerging countries presently benefit from the access to technologies that industrialised countries did not have 
access to at the time of their own development, hence the asymmetry goes both ways.

In order to overcome these criticisms, Baatz (2013) restates the beneficiary pays principle from the perspective of an egalitarian notion of distributive justice. The impacts of GHG emissions create a gap between those who benefit and those who are adversely affected by climate change (compared to an initial situation assumed to be fair), and Baatz thus proposes that this principle should be invoked to restore the equality of opportunity between all parties. However, following this line of argument, if a harmful act did not benefit anyone or if the beneficiaries were not able to compensate the victims (for instance, if they died), those victims would be left without compensation, which limits the scope and value of the principle (Huseby, 2015).

In addition to these conceptual hurdles, the prospect that historical emissions enter the climate governance appears rather bleak. The decision adopting the Paris Agreement explicitly excludes liability and compensation regarding loss and damages due to climate change (paragraph 51 of the decision commenting on article 8 of the Agreement that mentions the Warsaw Mechanism for Loss and Damage). It is therefore unclear how historical responsibility will now transpire in international relations (Petherick, 2016). The Warsam Mechanism will probably open the way to cooperation on risk management, resilience building, data sharing and prevention of meteorological catastrophes, rather than to extensive compensatory payments. This does not imply that any solidarity and assistance have been discarded. States still have duties towards the poorest worldwide regardless of climate justice issues, as other sources of moral concerns, not linked to justice, may be mobilised.

\section{Conclusion}

This review has highlighted the diversity of opinions and arguments on the principles of justice that may or should govern international cooperation on climate change. There are disputes between the supporters of international justice bound by the conditions of international cooperation and the supporters of a superseding cosmopolitan distributive justice directly addressing all human beings. There are also specific difficulties of proposals put forward, such as calls for equal rights of 
access to the atmosphere for every citizen of the world, or historical responsibility as a basis for allocating carbon emissions rights to countries. There can be cases of 'moral ambiguity' (Müller, 2001), that is, situations where equally justifiable principles could be applied but would lead to possibly contradictory outcomes. In those cases, whether one should apply one principle of justice or another depends on the context and on the available information about particular situations.

In the present state of the debate, no theory or proposal could become an attractor of international climate negotiations. Moreover, if one envisages operational rules sustaining a new climate regime, one must pay close attention to the instrument chosen to implement a just allocation of obligations and rights. An international market would transform, through monetisation, a physically grounded right into a portion of the general world wealth. This transformation would have consequences for defining an equitable allocation of quotas. The carbon market would turn the organisation of the access to a given physical good into a broader problem of distributive justice whose horizon would be nothing less than the fair sharing of global wealth (Godard, 1992, 2017). This explained the difficulty of implementing an international market for carbon quotas under Kyoto, in particular due to disputes on the initial allocation of emission rights (cf. Section 3.1).

Approaching climate justice as a global justice issue makes it too contentious to be solved. In practice, imposing schemes of climate justice has given way to pragmatic arrangements. The failure of the Copenhagen COP (2009) marked a return to a type of local justice, as negotiations have since become country-centred, based on voluntary commitments, without compensatory transfer mechanisms, although allowing for international aid towards the most vulnerable countries through the Green Climate Fund. The principle of 'common but differentiated responsibilities and respective capabilities' was reaffirmed in article 2 of the Paris Agreement, with a focus on the diversity of 'national circumstances': here again, climate change is considered as an issue of local justice.

The new Kigali amendment, which organizes the phasing out of hydrofluorocarbons (HFC, a potent type of GHG), of the Montreal Protocol tells a similar story. The Montreal Protocol took a local justice approach to phasing out ozone depleting substances. It offered specific provisions to developing countries and mechanisms for assistance but 
did not aim at reshaping global institutions and wealth. Thanks to the trust they have built, the institutions of the Montreal Protocol, originally designed to protect the ozone layer, now take part in the coordination of climate change mitigation efforts.

However, the all pervading nature of energy use and GHG emissions makes it difficult to find a local justice solution to climate change mitigation. As a global justice approach has not been successful either, overcoming this dead-end requires posing the climate justice question on new grounds. Many reasonings examined in this review are based on the implicit premise that emitting GHGs is necessary for development. Because the development of poor countries would and should not be constrained, they should be granted a carbon space. The overall carbon (or GHG) space is limited due to climate change, and thus should be shared fairly. As we have seen, this framing poses significant problems of justice.

The solution to cut this Gordian knot is to allow for the possibility of economic development without GHG emissions, so that everyone can thrive without having to share a limited carbon space (Hourcade et al., 2009). Sharing a carbon budget would no longer be needed, simply because carbon would no longer be needed. The 'equitable access to sustainable development' precisely calls for such a widening of possibilities. Indeed, the deployment of a new climate regime will be perceived as fair only if it contributes to opening the range of development paths (Ji and Sha, 2015). So how can we widen the space of possibilities? Part of the answer can be found in the Paris Agreement, which, in its article 2, sets the objective of 'making financial flows consistent with a pathway towards low greenhouse gas emissions and climate-resilient development'. As the financial system determines agents' expectations, it can either open new opportunities for an inclusive development or, on the contrary, create new sources of inequity. Its evolution is therefore crucial to achieve such a roadmap and to support investments in low carbon infrastructures and technologies. We guess that the climate justice problem will not be resolved through an adversarial process centered on how to share the carbon space, but only with a common vision of the benefits of low carbon development. 


\section{References}

Adler, M., D. Anthoff, V. Bosetti, G. Garner, K. Keller, and N. Treich. 2017. "Priority for the Worse-off and the Social Cost of Carbon". Nature Climate Change. 7(6): 443-9.

Agarwal, A. and S. Narain. 1991. "Global Warming in an Unequal World: A Case of Environmental Colonialism". Technical Report. New Dehli, India: Centre for Science and Environment.

AGBM. 1997. "Implementation of the Berlin Mandate: Proposal from Parties". Note by the Secretariat, Ad Hoc Group on the Berlin Mandate No. AGBM/1997/MISC1.

Agrawala, S. 1998. "Structural and Process History of the Intergovernmental Panel on Climate Change". Climatic Change. 39(4): 62142.

Allen, M. R., D. J. Frame, C. Huntingford, C. D. Jones, J. A. Lowe, M. Meinshausen, and N. Meinshausen. 2009. "Warming Caused by Cumulative Carbon Emissions Towards the Trillionth Tonne". Nature. 458(7242): 1163-6.

Anthoff, D., C. Hepburn, and R. S. Tol. 2009. "Equity Weighting and the Marginal Damage Costs of Climate Change". Ecological Economics. 68(3): 836-49.

Archer, D. and V. Brovkin. 2008. "The Millennial Atmospheric Lifetime of Anthropogenic CO2". Climatic Change. 90(3): 283-97.

Arrow, K. J., W. R. Cline, K.-G. Mäler, M. Munasinghe, R. Squitieri, and J. Stiglitz. 1995. "Intertemporal Equity, Discounting, and Economic Efficiency". In: Climate change 1995. Economic and social dimensions of climate change. Contribution of Working Group III to the Second Assessment Report of the Intergovernmental Panel on Climate Change. Ed. by P. Bruce, H. Lee, and E. Haites. Cambridge University Press. 125-44.

Azar, C. 1999. "Weight Factors in Cost-Benefit Analysis of Climate Change". Environmental and Resource Economics. 13(3): 249-68.

Baatz, C. 2013. "Responsibility for the Past? Some Thoughts on Compensating Those Vulnerable to Climate Change in Developing Countries". Ethics, Policy \& Environment. 16(1): 94-110. 
Baer, P. 2002. "Equity, Greenhouse Gas Emissions, and Global Common Resources". In: Climate Change Policy: A Survey. Ed. by S. H. Schneider, A. Rosencranz, and J. Niles. Washington: Island Press. 393-408.

Baer, P. 2013. "Who Should Pay for Climate Change? "Not Me"'. Chicago Journal of International Law. 13(2): 507-25.

Baer, P., T. Athanasiou, S. Kartha, and E. Kemp-Benedict. 2008. The Greenhouse Development Rights Framework: The Right to Development in a Climate Constrained World. Berlin: Heinrich Böll Foundation.

Barrett, S. 2003. Environment and Statecraft: The Strategy of Environmental Treaty-Making. Oxford New York: Oxford University Press.

Barrett, S. 2008. "The Incredible Economics of Geoengineering". Environmental and Resource Economics. 39: 45-54.

Beckerman, W. and J. Pasek. 2001. Justice, Posterity, and the Environment. Oxford: Oxford University Press.

Bell, D. 2011. "Global Climate Justice, Historic Emissions, and Excusable Ignorance". The Monist. 94(3): 391-411.

Berger, L. and J. Emmerling. 2017. "Welfare As Simple(X) Equity Equivalents". Technical Report. FEEM. FEEM Working Paper.

Botzen, W. J. W. and J. C. J. M. van den Bergh. 2014. "Specifications of Social Welfare in Economic Studies of Climate Policy: Overview of Criteria and Related Policy Insights". Environmental and Resource Economics. 58(1): 1-33.

Bovens, L. 2011. "A Lockean Defense of Grandfathering Emission Rights". In: The Ethics of Global Climate Change. Ed. by D. G. Arnold. Cambridge: Cambridge University Press. 124-44.

Byers, M. 1999. Custom, Power, and the Power of Rules: International Relations and Customary International Law. Cambridge [England] New York: Cambridge University Press.

Caney, S. 2005. "Cosmopolitan Justice, Responsibility, and Global Climate Change". Leiden Journal of International Law. 18(04): 74775 .

Caney, S. 2006. "Environmental Degradation, Reparations, and the Moral Significance of History". Journal of Social Philosophy. 37(3): 464-82.

Caney, S. 2009. "Justice and the Distribution of Greenhouse Gas Emissions1". Journal of Global Ethics. 5(2): 125-46. 
Caney, S. 2010a. "Climate Change and the Duties of the Advantaged". Critical Review of International Social and Political Philosophy. 13(1): 203-28.

Caney, S. 2010b. "Climate Change, Human Rights, and Moral Thresholds". In: Human Rights and Climate Change. Ed. by S. Humphreys. Cambridge: Cambridge University Press. 61-90.

Caney, S. 2011. "Climate Change, Energy Rights, and Equality". In: The Ethics of Global Climate Change. Ed. by D. G. Arnold. Cambridge: Cambridge University Press. 77-103.

Chakravarty, S., A. Chikkatur, H. D. Coninck, S. Pacala, R. Socolow, and M. Tavoni. 2009. "Sharing Global CO2 Emission Reductions Among One Billion High Emitters". Proceedings of the National Academy of Sciences. 106(29): 11884-8.

Chauvier, S. 2013. Éthique sans visage. Le problème des effets externes. Paris: Editions Vrin.

Chichilnisky, G. 1996. "An Axiomatic Approach to Sustainable Development". Social Choice and Welfare. 13(2): 231-57.

Chichilnisky, G. and G. M. Heal. 1994. "Who Should Abate Carbon Emissions?: An International Viewpoint". Economics Letters. 44(4): 443-9.

Chichilnisky, G. and G. M. Heal, eds. 2000. Environmental Markets: Equity and Efficiency. New York: Columbia University Press.

China. 2007. "China's National Climate Change Program". Technical Report. Beijing: National Development and Reform Commission. Cline, W. R. 1992. The Economics of Global Warming. Washington: Institute for International Economics.

Coase, R. H. 1960. "The Problem of Social Cost". Journal of Law and Economics. 3(October): 1-44.

Copp, D. 2005. "International Justice and the Basic Needs Principle". In: The Political Philosophy of Cosmopolitanism. Ed. by G. Brock and H. Brighouse. Cambridge: Cambridge University Press. 39-54. Coumou, D. and S. Rahmstorf. 2012. "A Decade of Weather Extremes". Nature Climate Change. 2(7): 491-6.

Delord, J. and L. Sébastien. 2010. "Pour une éthique de la dette écologique". VertigO - la revue électronique en sciences de l'environnement. 10(1). 
Dennig, F., M. B. Budolfson, M. Fleurbaey, A. Siebert, and R. H. Socolow. 2015. "Inequality, Climate Impacts on the Future Poor, and Carbon Prices". In: Proceedings of the National Academy of Sciences. Vol. 112. No. 52. 15827-32.

Dietz, S. and G. B. Asheim. 2012. "Climate Policy Under Sustainable Discounted Utilitarianism". Journal of Environmental Economics and Management. 63(3): 321-35.

Dumont, L. 1986. Essays on Individualism: Modern Ideology in Anthropological Perspective. Chicago: University of Chicago Press.

Dworkin, R. 2000. Sovereign Virtue: The Theory and Practice of Equality. Cambridge, MA: Harvard University Press.

Elster, J. 1992. Local Justice: How Institutions Allocate Scarce Goods and Necessary Burdens. New York: Russel Sage Foundation.

Elzen, M. G. J. D., J. G. J. Olivier, N. Höhne, and G. JanssensMaenhout. 2013. "Countries' Contributions to Climate Change: Effect of Accounting for All Greenhouse Gases, Recent Trends, Basic Needs and Technological Progress". Climatic Change. 121(2): 397-412.

Elzen, M. G. J. d., M. Schaeffer, and P. L. Lucas. 2005. "Differentiating Future Commitments on the Basis of Countries' Relative Historical Responsibility for Climate Change: Uncertainties in the Brazilian Proposal' in the Context of a Policy Implementation". Climatic Change. 71(3): 277-301.

European Council. 2000. "Resolution of the Council on the Precautionary Principle". In: Conclusions of the Presidency, Nice European Council. Nice.

Fankhauser, S., R. S. J. Tol, and D. W. Pearce. 1997. "The Aggregation of Climate Change Damages: a Welfare Theoretic Approach". Environmental and Resource Economics. 10(3): 249-66.

Fleurbaey, M. 2010. "Assessing Risky Social Situations". Journal of Political Economy. 118(4): 649-80.

Fleurbaey, M. and S. Zuber. 2013. "Climate Policies Deserve a Negative Discount Rate". Chicago Journal of International Law. 13(2): 56595.

Fleurbaey, M. and S. Zuber. 2015. "Discounting, Beyond Utilitarianism". Economics: The Open-Access, Open-Assessment E-Journal. 
France. 2009. "Copenhagen: A Project for the World". Technical Report. Available at: https://static.mediapart.fr/files/JusticeClimat.pdf. Paris: French Government.

Friman, M. and G. Strandberg. 2014. "Historical Responsibility for Climate Change: Science and the Science-Policy Interface". Wiley Interdisciplinary Reviews: Climate Change. 5(3): 297-316.

Frumhoff, P. C., R. Heede, and N. Oreskes. 2015. "The Climate Responsibilities of Industrial Carbon Producers". Climatic Change. 132(2): $157-71$.

Gardiner, S. M. 2011. A Perfect Moral Storm: The Ethical Tragedy of Climate Change. New York: Oxford University Press.

Gardiner, S. M., S. Caney, D. Jamieson, and H. Shue, eds. 2010. Climate Ethics: Essential Readings. New York: Oxford University Press.

Ghersi, F., J.-C. Hourcade, and P. Criqui. 2003. "Viable Responses to the Equity-Responsibility Dilemma: A Consequentialist View". Climate Policy. 3(Suppl. 1): S115-S133.

Godard, O. 1992. "Des marchés internationaux de droits à polluer pour le problème de l'effet de serre: de la recherche de l'efficacité aux enjeux de légitimité". Politiques et management public. 10(2): 10131.

Godard, O. 2009. "Time Discounting and Long-Run Issues: The Controversy Raised by the Stern Review of the Economics of Climate Change". OPEC Energy Review. 33(1): 1-22.

Godard, O. 2012. "Ecological Debt and Historical Responsibility Revisited: The Case of Climate Change". EUI Working Paper No. RSCAS 2012/46. Florence: European University Institute, Robert Schuman Center for Advanced Studies.

Godard, O. 2017. Global Climate Justice. Proposals, Arguments and Justification. Cheltenham, UK: Edward Elgar Publishing.

Goldemberg, J. and P. Guardabassi. 2015. "Burden Sharing in the Implementation of the Climate Convention". Energy Policy. 81: 5660 .

Goldemberg, J. and P. M. Guardabassi. 2012. "Climate Change and "Historical Responsibilities"'. Ambiente \&5 Sociedade. 15(1): 201-6.

Gosseries, A. 2004. "Historical Emissions and Free-Riding". Ethical Perspectives. 11(1): 36-60. 
Gosseries, A. 2005. "Cosmopolitan Luck Egalitarianism and the Greenhouse Effect". Canadian Journal of Philosophy. 35(Suppl. 1): 279309.

Government of India. 2009. "The Road to Copenhagen: India's Position on Climate Change Issues". Technical Report.

Grasso, M. 2012. "Sharing the Emission Budget". Political Studies. 60(3): 668-86.

Grubb, M. 1995. "Seeking Fair Weather: Ethics and the International Debate on Climate Change". International Affairs. 71(3): 463-96.

Ha-Duong, M. and N. Treich. 2004. "Risk Aversion, Intergenerational Equity and Climate Change". Environmental and Resource Economics. 28: 195-207.

Hansen, J., M. Sato, P. Kharecha, D. Beerling, R. Berner, V. MassonDelmotte, M. Pagani, M. Raymo, D. L. Royer, and J. C. Zachos. 2008. "Target Atmospheric CO2: Where Should Humanity Aim?" The Open Atmospheric Science Journal. 2(1): 217-31.

Heede, R. 2014. "Tracing Anthropogenic Carbon Dioxide and Methane Emissions to Fossil Fuel and Cement Producers, 1854-2010". Climatic Change. 122(1-2): 229-41.

Helm, C. and U. E. Simonis. 2001. "Distributive Justice in International Environmental Policy: Axiomatic Foundation and Exemplary Formulation". Environmental Values. 10(1): 5-18.

Hourcade, J.-C. and P. Shukla. 2013. "Triggering the Low-Carbon Transition in the Aftermath of the Global Financial Crisis". Climate Policy. 13(suppl. 1): 22-35.

Hourcade, J.-C., P. R. Shukla, and S. Mathy. 2009. "Untying the Climate-Development Gordian Knot. Economic Options in a Politically Constrained World". In: The Design of Climate Policy. Ed. by R. Guesnerie and H. Tulkens. Cambridge, MA: MIT Press. 75-99.

Huggel, C., D. Stone, M. Auffhammer, and G. Hansen. 2013. "Loss and Damage Attribution". Nature Climate Change. 3(8): 694-6.

Huggel, C., I. Wallimann-Helmer, D. Stone, and W. Cramer. 2016. "Reconciling Justice and Attribution Research to Advance Climate Policy". Nature Climate Change. 6(10): 901-8.

Huseby, R. 2015. "Should the Beneficiaries Pay?" Politics, Philosophy Es Economics. 14(2): 209-25.

International Climate Justice Network. 2002. "Bali Principles for Climate Justice". Technical Report. 
IPCC. 1990. Climate Change: The IPCC Scientific Assessment. Ed. by J. T. Houghton, G. J. Jenkins, and J. J. Ephraums. Cambridge; New York: Cambridge University Press.

Jacoby, H. D., R. Schmalensee, and I. Sue Wing. 1999. "Toward a Useful Architecture for Climate Change Negotiations".

Jamieson, D. 2001. "Climate Change and Global Environmental Justice". In: Changing the Atmosphere: Expert Knowledge and Environmental Governance. Ed. by C. A. Miller and P. N. Edwards. Cambridge, MA: MIT Press. 287-308.

Jamieson, D. 2013. "Climate Change, Consequentialism, and the Road Ahead". Chicago Journal of International Law. 13(2): 439-68.

Ji, Z. and F. Sha. 2015. "The Challenges of the Post-COP21 Regime: Interpreting CBDR in the INDC Context". International Environmental Agreements: Politics, Law and Economics. 15(4): 421-30.

Khor, M. 2009. "Historical Responsibility as a Guide to Future Action in Climate Charge". SBSTA Technical Briefing - 6th Meeting of the Ad Hoc Working Group on Long Term Cooperative Action. Berlin: UNFCCC.

Kingston, E. 2014. "Climate Justice and Temporally Remote Emissions:" Social Theory and Practice. 40(2): 281-303.

Koivurova, T., S. Duyck, and L. Heinämäki. 2013. "Climate Change and Human Rights". In: Climate Change and the Law. Ed. by E. J. Hollo, K. Kulovesi, and M. Mehling. Dordrecht New York: Springer. $287-325$.

Lecocq, F. and P. Ambrosi. 2007. "The Clean Development Mechanism: History, Status, and Prospects". Review of Environmental Economics and Policy. 1(1): 134-51.

Lecocq, F. and J.-C. Hourcade. 2012. "Unspoken Ethical Issues in the Climate Affair: Insights from a Theoretical Analysis of Negotiation Mandates". Economic Theory. 49(2): 445-71.

Locke, J. 1690. The Second Treatise of Civil Government. England: Awnsham Churchill.

Luderer, G., E. DeCian, J.-C. Hourcade, M. Leimbach, H. Waisman, and O. Edenhofer. 2012. "On the Regional Distribution of Mitigation Costs in a Global Cap-and-Trade Regime". Climatic Change. 114(1): 59-78.

Mary Robinson Foundation — Climate Justice. 2011. "Principles of Climate Justice". 
Matthews, H. D., S. Solomon, and R. Pierrehumbert. 2012. "Cumulative Carbon as a Policy Framework for Achieving Climate Stabilization". Philosophical Transactions of the Royal Society A: Mathematical, Physical and Engineering Sciences. 370(1974): 4365-79.

Meyer, A. 2000. Contraction \& Convergence: The Global Solution to Climate Change. Foxhole, Devon (UK): Green Books for the Schumacher Society.

Meyer, L. H. 2004. "Compensating Wrongless Historical Emissions of Greenhouse Gases". Ethical Perspectives. 11(1): 20-35.

Meyer, L. H. 2013. "Why Historical Emissions Should Count". Chicago Journal of International Law. 13(2): 598-614.

Miller, D. 2001. "Distributing Responsibilities". Journal of Political Philosophy. 9(4): 453-71.

Miller, D. 2007. National Responsibility and Global Justice. Oxford New York: Oxford University Press.

Miller, D. 2009. "Global Justice and Climate Change: How Should Responsibilities be Distributed?" In: The Tanner Lectures on Human Values. Ed. by G. B. Peterson. Vol. 28. Salt Lake City: University of Utah Press. 117-56.

Moellendorf, D. 2011. "Common Atmospheric Ownership and Equal Emissions Entitlements". In: The Ethics of Global Climate Change. Ed. by D. G. Arnold. Cambridge: Cambridge University Press. 10423.

Moellendorf, D. 2012. "Climate Change and Global Justice". Wiley Interdisciplinary Reviews: Climate Change. 3(2): 131-43.

Moellendorf, D. 2014. The Moral Challenge of Dangerous Climate Change: Values, Poverty, and Policy. New York: Cambridge University Press.

Müller, B. 2001. "Varieties of Distributive Justice in Climate Change". Climatic Change. 48(2-3): 273-88.

Müller, B., N. Höhne, and C. Ellermann. 2009. "Differentiating (Historic) Responsibilities for Climate Change". Climate Policy. 9(6): 593-611.

Neumayer, E. 2000. "In Defence of Historical Accountability for GreenHouse Gas Emissions". Ecological Economics. 33(2): 185-92.

Nordhaus, W. D. 1994. Managing the Global Commons: The Economics of Climate Change. Cambridge (MA): MIT Press.

Nordhaus, W. D. 2007. "A Review of the Stern Review on the Economics of Climate Change". Journal of Economic Literature. 45(3): 686-702. 
Nordhaus, W. and Z. Yang. 1996. "A Regional Dynamic GeneralEquilibrium Model of Alternative Climate-Change Strategies". American Economic Review. 86(4): 741-65.

OECD, ed. 1976. Economics of Transfrontier Pollution. Paris: Organisation for Economic Co-operation and Development.

Okereke, C. 2010. "Climate Justice and the International Regime". Wiley Interdisciplinary Reviews: Climate Change. 1(3): 462-74.

Okereke, C. and P. Coventry. 2016. "Climate Justice and the International Regime: Before, During, and after Paris". Wiley Interdisciplinary Reviews: Climate Change. 7(6): 834-51.

Otto, F. E. L. 2016. "Extreme Events: The Art of Attribution". Nature Climate Change. 6(4): 342-3.

Page, E. A. 2012. "Give it Up for Climate Change: A Defence of the Beneficiary Pays Principle". International Theory. 4(02): 300-30.

Paredis, E., J. Lambrecht, G. Goeminne, and W. Vanhove. 2004. "VLIRBVO Project 2003 'Elaboration of the Concept of Ecological Debt"'. Technical Report. Centre for Sustainable Development (CDO) Ghent University. 234.

Parfit, D. 1984. Reasons and Persons. Oxford University Press.

Parikh, J. and K. Parikh. 2009. "Climate Change: A Parking Place Model for A Just Global Compact". Technical Report.

Petherick, A. 2016. "Loss and Damage Post Paris". Nature Climate Change. 6(8): 741.

Piketty, T. and L. Chancel. 2015. "Carbon and Inequality: From Kyoto to Paris. Trends in the Global Inegality of Carbon Emissions (19982013) \& Prospects for an Equitable Adaptation Fund". Paris.

Pogge, T. W. 1994. "An Egalitarian Law of Peoples". Philosophy \& Public Affairs. 23(3): 195-224.

Posner, E. A. and C. R. Sunstein. 2009. "Should Greenhouse Gas Permits Be Allocated on a per Capita Basis?" California Law Review. 97(1): 51-93.

Posner, E. A. and D. A. Weisbach. 2010. Climate Change Justice. Princeton, NJ: Princeton University Press.

Posner, E. and D. Weisbach. 2013. "International Paretianism: A Defense". Chicago Journal of International Law. 13(2): 347-58.

Rajamani, L. 2012. "The Durban Platform for Enhanced Action and the Future of the Climate Regime". International \& Comparative Law Quarterly. 61(02): 501-18. 
Ranson, M. and R. N. Stavins. 2012. "Post-Durban Climate Policy Architecture Based on Linkage of Cap-and-Trade Systems". Working Paper No. 18140. National Bureau of Economic Research.

Rawls, J. 1971. A Theory of Justice. Cambridge, MA: Belknap. Rawls, J. 1993. "The Law of Peoples". Critical Inquiry. 20(1): 36-68. Raymond, L. S. 2003. Private Rights in Public Resources: Equity and Property Allocation in Market-Based Environmental Policy. Washington (DC): Resources for the Future.

Risse, M. 2012. On Global Justice. Princeton: Princeton University Press.

Robertson, H. G. 1995. "If Your Grandfather Could Pollute, So Can You: Environmental Grandfather Clauses and Their Role in Environmental Inequality". Catholic University Law Review. 45: 13179.

Roemer, J. E. 2011. "The Ethics of Intertemporal Distribution in a Warming Planet". Environmental and Resource Economics. 48(3): 363-90.

Schlosberg, D. and L. B. Collins. 2014. "From Environmental to Climate Justice: Climate Change and the Discourse of Environmental Justice". Wiley Interdisciplinary Reviews: Climate Change. 5(3): 359-74.

Schmidt, M. G. W., H. Held, E. Kriegler, and A. Lorenz. 2013. "Climate Policy Under Uncertain and Heterogeneous Climate Damages". Environmental and Resource Economics. 54(1): 79-99.

Schüssler, R. 2011. "Climate Justice: A Question of Historic Responsibility?" Journal of Global Ethics. 7(3): 261-78.

Sen, A. 1979. "Equality of What? Tanner Lecture on Human Values". In: Tanner Lectures. Stanford University.

Sen, A. 1992. Inequality Reexamined. New York Cambridge, (MA): Russell Sage Foundation Harvard University Press.

Shiell, L. 2003. "Equity and Efficiency in International Markets for Pollution Permits". Journal of Environmental Economics and Management. 46(1): 38-51.

Shue, H. 1999. "Global Environment and International Inequality". International Affairs. 75(3): 531-45.

Shue, H. 2009. "Historical responsibility: accountability for the results of actions taken". SBSTA Technical Briefing - 6th Meeting of the Ad Hoc Working Group on Long Term Cooperative Action. Berlin: CCNUCC. 
Shue, H. 2011. "Human Rights, Climate Change, and the Trillionth Ton". In: The Ethics of Global Climate Change. Ed. by D. G. Arnold. Cambridge: Cambridge University Press. 292-314.

Shue, H. 2014. Climate Justice: Vulnerability and Protection. 1st. Oxford: Oxford University Press.

Shukla, P. R. 1999. "Justice, Equity and Efficiency in Climate Change: A Developing Country Perspective". In: Fair Weather? Equity Concerns in Climate Change. Ed. by F. L. Tóth. London: Earthscan. 145-59. Singer, P. 2002. "One Atmosphere". In: One World: The Ethics of Globalization. Ed. by P. Singer. New Haven: Yale University Press. 14-50.

Smith, K. R., J. Swisher, and D. R. Ahuja. 1993. "Who Pays (To Solve the Problem and How Much)?" In: The Global Greenhouse Regime: Who Pays? Ed. by P. Hayes and K. R. Smith. Earthscan.

Stanton, E. A. 2011. "Negishi Welfare Weights in Integrated Assessment

Models: The Mathematics of Global Inequality". Climatic Change. 107(3-4): 417-32.

Starkey, R. 2011. "Assessing Common(s) Arguments for an Equal per Capita Allocation". The Geographical Journal. 177(2): 112-26.

State of Bolivia. 2009. "Climate Debt: The Basis of a Fair and Effective

Solution to Climate Change". 6th Meeting of the Ad Hoc Working Group on Long-Term Cooperative Action. Berlin: UNFCCC.

Stern, N. 2006. The Stern Review on the Economics of Climate Change.

English. Cambridge, UK: Cambridge University Press. ISBN: 0-52170080-9 978-0-521-70080-1.

Stern, N. 2014a. "Ethics, Equity and the Economics Of Climate Change.

Paper 1: Science and Philosophy". Economics and Philosophy. 30(3): 397-444.

Stern, N. 2014b. "Ethics, Equity and the Economics of Climate Change. Paper 2: Economics and Politics". Economics and Philosophy. 30(3): $445-501$.

Sunstein, C. R. 2005. Laws of Fear: Beyond the Precautionary Principle. Cambridge, UK New York: Cambridge University Press.

Tavoni, M., E. Kriegler, T. Aboumahboub, K. Calvin, G. De Maere, M. Wise, D. Klein, J. Jewell, T. Kober, P. Lucas, G. Luderer, D. McCOLLUM, G. Marangoni, K. Riahi, and D. Van Vuuren. 2013. "The Distribution of the Major Economies' Effort in the urban Platform Scenarios". Climate Change Economics. 04(04): 1340009. 
Teng, F. 2009. "Historical Responsibility From a Perspective of Per Capita Cumulative Emissions". SBSTA Technical Briefing - 6th Meeting of the Ad Hoc Working Group on Long Term Cooperative Action. Berlin: UNFCCC.

Tol, R. S. J. 1998. "Short-term Decisions Under Long-Term Uncertainty". Energy Economics. 20(5-6): 557-69.

Tol, R. S. J. 2001. "Equitable Cost-Benefit Analysis of Climate Change Policies". Ecological Economics. 36(1): 71-85.

UNFCCC. 1998. "Preparatory Work Needed for the Fourth Session of the Conference of the Parties on the Items Listed in Decision 1/CP.3, Paragraph 5". Technical Report No. FCCC/SB/1998/MISC.1/Add.3/ Rev.1. Bonn: UNFCCC/SBSTA.

Vanderheiden, S. 2008. Atmospheric Justice: A Political Theory of Climate Change. Oxford New York: Oxford University Press.

Varian, H. R. 1974. "Equity, Envy, and Efficiency". Journal of Economic Theory. 9(1): 63-91.

Weitzman, M. L. 2007. "A Review of the Stern Review on the Economics of Climate Change". Journal of Economic Literature. 45(3): 703-24. Winkler, H., T. Jayaraman, J. Pan, A. S. de Oliveira, Y. Zhang, G. Sant, J. D. G. Miguez, T. Letete, A. Marquard, and S. Raubenheimer. 2011. "Equitable Access to Sustainable Development". Contribution to the Body of Scientific Knowledge: A Paper by Experts from BASIC Countries, BASIC Expert Group: Beijing, Brasilia, Cape Town and Mumbai.

WRI. 2017. "CAIT Climate Data Explorer". Available at: http://cait. wri.org.

Young, H. P. and A. Wolf. 1992. "Global Warming Negotiations: Does Fairness Matters?" Brookings Review No. 10. 46-51. 